\title{
Evaluation of the Effect of Brazilian Savanna (Cerrado) Seasons in Flavonoids and Alkaloids Accumulation: The Case of Duguetia furfuracea
}

\author{
Arthur L. Macedo, ${ }^{a}$ Amanda G. Boaretto, ${ }^{a}$ André N. da Silva, ${ }^{a}$ Débora S. Maia, ${ }^{b}$ \\ João M. de Siqueira, ${ }^{b}$ Denise B. Silva ${ }^{a}$ and Carlos A. Carollo ${ }^{\circledR} *, a$ \\ ${ }^{a}$ Laboratório de Produtos Naturais e Espectrometria de Massas, \\ Faculdade de Ciências Farmacêuticas, Alimentos e Nutrição, \\ Universidade Federal de Mato Grosso do Sul, 79070-900 Campo Grande-MS, Brazil \\ ${ }^{b}$ Laboratório de Farmacognosia/Química de Produtos Naturais, \\ Universidade Federal de São João del-Rei, Campus Centro-Oeste Dona Lindu, \\ 35501-296 Divinópolis-MG, Brazil
}

\begin{abstract}
Environmental factors can influence secondary plant metabolism, inducing seasonal variation in chemical composition. Few works report how the seasons of Brazilian savanna (Cerrado), rainy and dry, impacts plant metabolism. We investigated the seasonal effect on the production of secondary metabolites in Duguetia furfuracea. Leaves of three individuals were collected monthly for one year and analyzed by ultra-fast liquid chromatography coupled to diode array detector and mass spectrometry (UFLC-DAD-MS), partial least squares-discriminant analysis (PLS-DA), hierarchical cluster analysis (HCA), volcano plot, and Pearson correlation. The main chemical classes found were benzyltetrahydroisoquinoline derivatives and flavonoids. Alkaloids are virtually perennial, with qualitative variation during the year, and flavonoids accumulate during the rainy season. Dew point temperature seemed to be the most representative weather indicator in the metabolite change. These results showed for the first time the effect of the Cerrado environment on the levels of flavonoids and alkaloids in Duguetia furfuracea. They could be useful for exploring this species since it is used in popular medicine and accumulates valuable secondary metabolites.
\end{abstract}

Keywords: alkaloids, Duguetia furfuracea, flavonoids, metabolomics, seasonality

\section{Introduction}

Secondary plant metabolites are associated with distinct biological functions. ${ }^{1}$ Although secondary metabolites synthesis is under genetic control, it can be modulated by ecological, physiological, biological, biochemical, and evolutionary factors. ${ }^{2}$

Due to the influence of environmental factors on secondary plant metabolism, the amounts and production of these compounds can be affected, for example, by seasonality. ${ }^{2}$ For plants used as medicines, the harvest period is crucial once the abundance of active compounds can be drastically distinct during the year. ${ }^{3}$ Such variation has been reported for many classes that are used as chemical markers in quality control in international pharmacopeial compendiums, such as terpenoids, saponins, alkaloids, tannins, coumarins, flavonoids, and iridoids. ${ }^{4-10}$ In this way, knowledge of metabolite accumulation patterns is essential

*e-mail: carlos.carollo@ufms.br for the standardization of cultures in large-scale production or sustainable plant exploitation.

Brazilian savanna (Cerrado) is characterized by seasonality with two periods: rainy and dry. ${ }^{11}$ Few reports on the influence of this microclimatic variation on metabolite contents can be found in the literature. This biome is the second largest in Brazil and is considered a global biodiversity hotspot due to the high abundance of endemic species. ${ }^{12}$ Among the 11,627 native plant species already cataloged, at least 220 have medicinal uses, and metabolic variation can directly influence their quality and safety use. ${ }^{13}$

Duguetia furfuracea (A.St.-Hil.) Saff. (Annonaceae) is a shrub that grows in several Brazil regions and has a widespread distribution in the Cerrado. ${ }^{14}$ This species is popularly known as "araticum-seco", ${ }^{14}$ and in Brazilian folk medicine, the leaves are used to treat renal colic and rheumatism. ${ }^{15}$ Compounds isolated from D. furfuracea showed several biological properties, especially alkaloids. Santos et al..$^{15}$ recently reported that the alkaloids 
duguetine, dicentrinone, and $\mathrm{N}$-methylglucamine are the major compounds present in the extract of this species with antirheumatic activity, which is associated with the ethnopharmacological applications of the species. The authors also demonstrated the higher content of flavonoids in this extract than in other less active. Thus, the present study aimed to investigate the seasonality effect on the production of alkaloids and flavonoids in the leaves of the species $D$. furfuracea as a model to evaluate metabolite fluctuation in Cerrado plants.

\section{Results}

\section{Climate evaluation}

Hierarchical cluster analysis (HCA) uses the Ward clustering algorithm and Pearson or Euclidean distances. In the results from Pearson analysis, the dry season was characterized by a low relative humidity $\left(\mathrm{H}_{\mathrm{rel}}\right)$ and dew point temperature $\left(\mathrm{DPT}_{\mathrm{a}}\right.$ ) and high atmospheric pressure (AP). On the other hand, the rainy months presented higher average and minimum air temperatures $\left(\mathrm{T}_{\mathrm{a}}\right.$ and $\left.\mathrm{T}_{\min }\right)$ and a higher minimum DPT ( $\mathrm{DPT}_{\text {min }}$ ) than the dry months. These factors were important for clustering all rainy months, except April. Although the total precipitation (PPT), $\mathrm{H}_{\mathrm{rel}}$ and $\mathrm{DPT}_{\mathrm{a}}$ tended to be higher in the months grouped into the rainy season, in general, there was no pattern.

In the Euclidean distance-based HCA (Figure S1b, Supplementary Information (SI) section), the high averages of air $\mathrm{T}_{\mathrm{a}}, \mathrm{T}_{\text {min }}$, and $\mathrm{DPT}_{\text {min }}$ were crucial to group the rainy months. The high average precipitation (PPT) and relative humidity $\left(\mathrm{H}_{\mathrm{rel}}\right)$ also tended to cluster these months. As observed in the Pearson HCA, AP was relevant for distinguishing the dry months.

Principal component analysis (PCA) did not totally separate the seasons (Figure S1c, SI section). The analysis demonstrated that the months initially assumed to be part of the rainy season were tightly grouped. The dry months were more sparsely grouped, indicating that the dry season exhibited more variation than the rainy season in the analyzed climatic parameters.

In this way, the climate data observed for the year when the study was performed revealed that the periods of November 2015 to April 2016 and November 2016 could be considered the rainy season, while June to October 2016 could be classified as the dry season. Once April 2016 was grouped with the rainy months in PCA and dry months in HCA using Pearson distances and May and October 2016 were clustered with the dry months in PCA and rainy months in HCA using Euclidean distances, these three months were considered seasonal transition months.

\section{Chemical composition}

The alignment and reduction of entrances of the data obtained from ultra-fast liquid chromatography mass spectrometry coupled to diode array detector (UFLC-DAD-MS), analysis of the leaf extracts from D. furfuracea resulted in 78 compounds (Table 1). In the UFLC-DAD-MS/MS data, the main compound putative classes found in these extracts were benzyltetrahydroisoquinoline alkaloids (BTAs: 6, 8-10, 19, 25, 26, 47, 49, and 56), aporphine alkaloids (AAs: 14, 20, 21, 23, 29, 31-34, 41, 50-52, and 55), (bis)benzyltetrahydroisoquinoline alkaloids (BBTAs: 30, 40, 43, 46, and 53), proanthocyanidins (PCs: 7, 11-13, 16, 17, 24, 27, 28, and 37), flavonols (Fols: 38, $39,42,44,45,64$, and 65 ) and flavones (Fones: 58-62, 66-68). Besides, proaporphine (15) and tetrahydroprotoberberine (18) alkaloids, dihydroflavonol (57), hydrocarbons $(\mathbf{6 9}, \mathbf{7 0}, \mathbf{7 2}$, 73), chlorophyll derivatives (75-77), and 13 other compounds (Table 1).

Among these compounds, $\mathbf{1 3}$ and $\mathbf{5 0}$ were identified by injecting authentic standards as epicatechin and anonaine. The other compounds were putatively identified according to their MS/MS and UV spectra and are presented in the SI section, Table S1.

\section{Multivariate statistical analysis}

The cross-validation of the model generated by partial least squares-discriminant analysis (PLS-DA) presented coefficient of determination $\left(\mathrm{R}^{2}\right)=0.89991$ and crossvalidation coefficient of determination $\left(Q^{2}\right)=0.70055$ for two components, reaching $\mathrm{R}^{2}=0.99741$ and $\mathrm{Q}^{2}=0.90644$ for five components, which is considered a suitable method for the discrimination between dry and rainy seasons. Analyzing Figure 1a, we can observe the groups separated mainly by component $1(53.4 \%)$. Although grouped with the rainy ones, November's months are sparser, separated from the other by component $2(16 \%)$.

The variable importance in projection (VIP) scores plot (Figure 1b) indicated that alkaloids 21, 23, 29, 52, 45, 14, 48 (AA), and 9 (BTA) were more accumulated in the dry season. In contrast, flavonoids $67,66,61,65,68,64,59$, and 62 and alkaloids 51, 31 (AA), 49 (BTA), and 15 (PAA) were more accumulated in the rainy season.

The heatmap from HCA (Figure 2) also displayed a clear separation of dry and rainy months. Two major compound clusters can be observed, being one majorly composed of alkaloids (cluster A) and the other of flavonoids and proanthocyanidins (cluster B). Each of these clusters is branched into two others. Compounds of clusters A2 and B2 seem to be more susceptible to 
Table 1. List of annotated compounds obtained with UFLC-DAD-MS/MS analysis of the extracts from leaves of Duguetia furfuracea on positive and negative modes

\begin{tabular}{|c|c|c|c|}
\hline No. & Compound & $\mathrm{t}_{\mathrm{R}} / \min$ & Molecular formula \\
\hline \multicolumn{4}{|c|}{ Benzyltetrahydroisoquinoline alkaloids (BTA) } \\
\hline 6 & reticuline isomer 1 & 8.9 & $\mathrm{C}_{19} \mathrm{H}_{23} \mathrm{NO}_{4}$ \\
\hline 8 & reticuline isomer 2 & 10.3 & $\mathrm{C}_{19} \mathrm{H}_{23} \mathrm{NO}_{4}$ \\
\hline 9 & $O$-demethyl reticuline & 11.0 & $\mathrm{C}_{18} \mathrm{H}_{21} \mathrm{NO}_{4}$ \\
\hline 10 & oblongine/lotusine isomer 1 & 11.2 & $\mathrm{C}_{19} \mathrm{H}_{24} \mathrm{NO}_{3}^{+}$ \\
\hline 19 & tembetarine isomer & 13.8 & $\mathrm{C}_{20} \mathrm{H}_{26} \mathrm{NO}_{4}^{+}$ \\
\hline 25 & reticuline $^{\mathrm{a}}$ & 15.1 & $\mathrm{C}_{19} \mathrm{H}_{23} \mathrm{NO}_{4}$ \\
\hline 26 & oblongine/lotusine isomer 2 & 15.3 & $\mathrm{C}_{19} \mathrm{H}_{24} \mathrm{NO}_{3}^{+}$ \\
\hline 47 & colletine isomer & 21.8 & $\mathrm{C}_{20} \mathrm{H}_{26} \mathrm{NO}_{3}^{+}$ \\
\hline 49 & deoxyreticuline & 22.2 & $\mathrm{C}_{19} \mathrm{H}_{23} \mathrm{NO}_{3}$ \\
\hline 56 & dehydronorreticuline & 24.8 & $\mathrm{C}_{18} \mathrm{H}_{19} \mathrm{NO}_{4}$ \\
\hline \multicolumn{4}{|c|}{ Aporphine alkaloids (AA) } \\
\hline 14 & dimethoxy-dihydroxy AA & 12.8 & $\mathrm{C}_{18} \mathrm{H}_{19} \mathrm{NO}_{4}$ \\
\hline \multirow{2}{*}{20} & $N$-methyl dimethoxy-dihydroxy AA & 13.9 & $\mathrm{C}_{19} \mathrm{H}_{21} \mathrm{NO}_{4}$ \\
\hline & norcoridine & 13.9 & $\mathrm{C}_{19} \mathrm{H}_{21} \mathrm{NO}_{4}$ \\
\hline 21 & anolobine & 13.9 & $\mathrm{C}_{17} \mathrm{H}_{15} \mathrm{NO}_{3}$ \\
\hline 23 & magnoflorine & 14.6 & $\mathrm{C}_{20} \mathrm{H}_{24} \mathrm{NO}_{4}^{+}$ \\
\hline 29 & nor(iso)corydine isomer $1^{\text {a }}$ & 16.5 & $\mathrm{C}_{19} \mathrm{H}_{21} \mathrm{NO}_{4}$ \\
\hline 31 & asimilobine $^{\mathrm{a}}$ & 16.9 & $\mathrm{C}_{17} \mathrm{H}_{17} \mathrm{NO}_{2}$ \\
\hline 32 & nor(iso)corydine isomer $2^{\mathrm{a}}$ & 17.0 & $\mathrm{C}_{19} \mathrm{H}_{21} \mathrm{NO}_{4}$ \\
\hline 33 & (iso)corydine isomer $1^{\mathrm{a}, \mathrm{b}}$ & 17.1 & $\mathrm{C}_{20} \mathrm{H}_{23} \mathrm{NO}_{4}$ \\
\hline 34 & (iso)corydine isomer $2^{\mathrm{a}, \mathrm{b}}$ & 17.5 & $\mathrm{C}_{20} \mathrm{H}_{23} \mathrm{NO}_{4}$ \\
\hline 41 & (iso)corydine isomer $3^{\mathrm{a}, \mathrm{b}}$ & 19.3 & $\mathrm{C}_{20} \mathrm{H}_{23} \mathrm{NO}_{4}$ \\
\hline 48 & methyl (iso)corydine & 22.2 & $\mathrm{C}_{21} \mathrm{H}_{25} \mathrm{NO}_{4}$ \\
\hline 50 & anonaine $^{\mathrm{a}, \mathrm{c}}$ & 22.8 & $\mathrm{C}_{17} \mathrm{H}_{15} \mathrm{NO}_{2}$ \\
\hline 51 & $N$-nornuciferine ${ }^{\mathrm{b}}$ & 23.0 & $\mathrm{C}_{18} \mathrm{H}_{19} \mathrm{NO}_{2}$ \\
\hline 52 & romerine & 23.1 & $\mathrm{C}_{18} \mathrm{H}_{17} \mathrm{NO}_{2}$ \\
\hline 55 & xylopine $^{\mathrm{a}}$ & 24.5 & $\mathrm{C}_{18} \mathrm{H}_{17} \mathrm{NO}_{3}$ \\
\hline \multicolumn{4}{|c|}{ Proaporphine alkaloids (PAA) } \\
\hline 15 & stepharine & 13.1 & $\mathrm{C}_{18} \mathrm{H}_{19} \mathrm{NO}_{3}$ \\
\hline \multicolumn{4}{|c|}{ Tetrahydroprotoberberine alkaloids (TPA) } \\
\hline 18 & discretamine $^{\mathrm{a}}$ & 13.7 & $\mathrm{C}_{19} \mathrm{H}_{21} \mathrm{NO}_{4}$ \\
\hline \multicolumn{4}{|c|}{ (Bis)benzyltetrahydroisoquinoline alkaloids (BBTA) } \\
\hline 3 & BBTA mono linked & 16.9 & $\mathrm{C}_{36} \mathrm{H}_{40} \mathrm{~N}_{2} \mathrm{O}_{6}$ \\
\hline 40 & isochondodendrine isomer $1^{\mathrm{a}}$ & 19.0 & $\mathrm{C}_{36} \mathrm{H}_{38} \mathrm{~N}_{2} \mathrm{O}_{6}$ \\
\hline 43 & isochondodendrine isomer $2^{\mathrm{a}}$ & 19.8 & $\mathrm{C}_{36} \mathrm{H}_{38} \mathrm{~N}_{2} \mathrm{O}_{6}$ \\
\hline 46 & BBTA mono linked & 21.6 & $\mathrm{C}_{37} \mathrm{H}_{40} \mathrm{~N}_{2} \mathrm{O}_{6}$ \\
\hline 53 & BBTA mono linked & 23.8 & $\mathrm{C}_{37} \mathrm{H}_{40} \mathrm{~N}_{2} \mathrm{O}_{6}$ \\
\hline \multicolumn{4}{|c|}{ Proanthocyanidins (PC) } \\
\hline 7 & procyanidin dimer (B type) isomer 1 & 9.3 & $\mathrm{C}_{30} \mathrm{H}_{24} \mathrm{O}_{12}$ \\
\hline 11 & procyanidin dimer (B type) isomer 2 & 12.2 & $\mathrm{C}_{30} \mathrm{H}_{26} \mathrm{O}_{12}$ \\
\hline 12 & procyanidin trimer (B type) isomer 1 & 12.4 & $\mathrm{C}_{45} \mathrm{H}_{38} \mathrm{O}_{18}$ \\
\hline 13 & epicatechin ${ }^{\mathrm{c}}$ & 12.6 & $\mathrm{C}_{15} \mathrm{H}_{14} \mathrm{O}_{6}$ \\
\hline 16 & procyanidin tetramer (B type) isomer 1 & 13.2 & $\mathrm{C}_{60} \mathrm{H}_{50} \mathrm{O}_{24}$ \\
\hline 17 & procyanidin tetramer (B type) isomer 2 & 13.6 & $\mathrm{C}_{60} \mathrm{H}_{50} \mathrm{O}_{24}$ \\
\hline 24 & procyanidin trimer (B type) isomer 2 & 14.8 & $\mathrm{C}_{45} \mathrm{H}_{38} \mathrm{O}_{18}$ \\
\hline 27 & procyanidin tetramer (B type) isomer 3 & 15.6 & $\mathrm{C}_{60} \mathrm{H}_{50} \mathrm{O}_{24}$ \\
\hline 28 & procyanidin trimer (B type) isomer 3 & 16.1 & $\mathrm{C}_{45} \mathrm{H}_{38} \mathrm{O}_{18}$ \\
\hline 37 & procyanidin dimer (B type) isomer 3 & 18.6 & $\mathrm{C}_{30} \mathrm{H}_{26} \mathrm{O}_{12}$ \\
\hline \multicolumn{4}{|c|}{$\begin{array}{ll}\text { Flavonols (Fol) } \\
\end{array}$} \\
\hline 38 & $O$-deoxyhexosyl-hexosyl quercetin & 18.7 & $\mathrm{C}_{27} \mathrm{H}_{30} \mathrm{O}_{16}$ \\
\hline 39 & tri-O-deoxyhexosyl kaempferol & 18.9 & $\mathrm{C}_{32} \mathrm{H}_{38} \mathrm{O}_{19}$ \\
\hline 42 & $O$-hexosyl-coumaroyl kaempferol & 19.7 & $\mathrm{C}_{30} \mathrm{H}_{26} \mathrm{O}_{13}$ \\
\hline 44 & $O$-deoxyhexosyl-hexosyl $O$-methyl quercetin & 21.0 & $\mathrm{C}_{28} \mathrm{H}_{32} \mathrm{O}_{16}$ \\
\hline 45 & $O$-deoxyhexosyl-hexosyl $O$-methyl quercetin & 21.4 & $\mathrm{C}_{28} \mathrm{H}_{32} \mathrm{O}_{16}$ \\
\hline
\end{tabular}


Table 1. List of annotated compounds obtained with UFLC-DAD-MS/MS analysis of the extracts from leaves of Duguetia furfuracea on positive and negative modes (cont.)

\begin{tabular}{|c|c|c|c|}
\hline No. & Compound & $t_{R} / \min$ & Molecular formula \\
\hline 64 & $O$-hexosyl-dicoumaroyl kaempferol & 31.2 & $\mathrm{C}_{39} \mathrm{H}_{32} \mathrm{O}_{15}$ \\
\hline 65 & $O$-deoxyhexosyl-hexosyl-coumaroyl $O$-methyl quercetin & 31.3 & $\mathrm{C}_{37} \mathrm{H}_{38} \mathrm{O}_{18}$ \\
\hline \multicolumn{4}{|c|}{$\begin{array}{ll} & \text { Dihydroflavonol (DFol) } \\
\end{array}$} \\
\hline 57 & $O$-deoxyhexosyl-hexosyl-glucoronyl- dihydroquercetin & 25.7 & $\mathrm{C}_{32} \mathrm{H}_{38} \mathrm{O}_{21}$ \\
\hline \multicolumn{4}{|c|}{$\begin{array}{ll}\text { Flavones (Fone) } \\
\end{array}$} \\
\hline 58 & $O$-deoxyhexosyl-coumaroyl luteolin & 27.9 & $\mathrm{C}_{30} \mathrm{H}_{26} \mathrm{O}_{13}$ \\
\hline 59 & $O$-deoxyhexosyl-hexosyl methoxyluteolin & 28.6 & $\mathrm{C}_{28} \mathrm{H}_{32} \mathrm{O}_{16}$ \\
\hline 60 & $O$-deoxyhexosyl-coumaroyl luteolin & 28.7 & $\mathrm{C}_{30} \mathrm{H}_{26} \mathrm{O}_{13}$ \\
\hline 61 & di- $O$-hexosyl-coumaroyl methoxyluteolin & 28.9 & $\mathrm{C}_{37} \mathrm{H}_{38} \mathrm{O}_{18}$ \\
\hline 62 & $O$-hexosyl-dicoumaroyl luteolin & 30.5 & $\mathrm{C}_{39} \mathrm{H}_{32} \mathrm{O}_{15}$ \\
\hline 66 & $O$-hexosyl-dicoumaroyl luteolin & 31.8 & $\mathrm{C}_{39} \mathrm{H}_{32} \mathrm{O}_{15}$ \\
\hline 67 & $O$-hexosyl-dicoumaroyl luteolin & 32.0 & $\mathrm{C}_{39} \mathrm{H}_{32} \mathrm{O}_{15}$ \\
\hline 68 & di-O-deoxyhexosyl-coumaroyl methoxyluteolin & 32.1 & $\mathrm{C}_{37} \mathrm{H}_{38} \mathrm{O}_{18}$ \\
\hline \multicolumn{4}{|c|}{ Other compounds } \\
\hline 1 & unknown & 1.0 & $\mathrm{C}_{6} \mathrm{H}_{4} \mathrm{O}_{6}$ \\
\hline 2 & unknown & 1.0 & $\mathrm{C}_{6} \mathrm{H}_{8} \mathrm{~N}_{4} \mathrm{O}_{3}$ \\
\hline 3 & unknown & 1.1 & $\mathrm{C}_{20} \mathrm{H}_{33} \mathrm{NO}_{4}$ \\
\hline 4 & unknown & 1.2 & $\mathrm{C}_{12} \mathrm{H}_{22} \mathrm{O}_{11}$ \\
\hline 5 & unknown & 3.8 & $\mathrm{C}_{9} \mathrm{H}_{15} \mathrm{NO}_{7}$ \\
\hline 22 & unknown & 14.1 & $\mathrm{C}_{23} \mathrm{H}_{21} \mathrm{NO}_{8}$ \\
\hline 35 & unknown & 17.6 & $\mathrm{C}_{23} \mathrm{H}_{21} \mathrm{NO}_{8}$ \\
\hline 36 & unknown & 18.4 & $\mathrm{C}_{29} \mathrm{H}_{39} \mathrm{~N}_{5} \mathrm{O}_{9}$ \\
\hline 54 & unknown & 24.0 & $\mathrm{C}_{15} \mathrm{H}_{22} \mathrm{O}$ \\
\hline 63 & unknown & 31.0 & $\mathrm{C}_{15} \mathrm{H}_{22} \mathrm{O}$ \\
\hline 69 & hydrocarbon 1 & 37.7 & $\mathrm{C}_{15} \mathrm{H}_{22}$ \\
\hline 70 & hydrocarbon 2 & 38.0 & $\mathrm{C}_{15} \mathrm{H}_{22}$ \\
\hline 71 & unknown & 38.2 & $\mathrm{C}_{27} \mathrm{H}_{41} \mathrm{~N}_{7} \mathrm{O}_{2}$ \\
\hline 72 & hydrocarbon 3 & 38.4 & $\mathrm{C}_{15} \mathrm{H}_{22}$ \\
\hline 73 & hydrocarbon 4 & 39.2 & $\mathrm{C}_{15} \mathrm{H}_{22}$ \\
\hline 74 & unknown & 42.7 & $\mathrm{C}_{60} \mathrm{H}_{78} \mathrm{O}_{10}$ \\
\hline 75 & pheophorbide a & 43.3 & $\mathrm{C}_{35} \mathrm{H}_{36} \mathrm{~N}_{4} \mathrm{O}_{5}$ \\
\hline 76 & methyl pheophorbide $b$ & 43.7 & $\mathrm{C}_{36} \mathrm{H}_{36} \mathrm{~N}_{4} \mathrm{O}_{6}$ \\
\hline 77 & pheophorbide a' & 43.8 & $\mathrm{C}_{35} \mathrm{H}_{36} \mathrm{~N}_{4} \mathrm{O}_{5}$ \\
\hline 78 & unknown & 44.8 & $\mathrm{C}_{37} \mathrm{H}_{64} \mathrm{O}_{5}$ \\
\hline
\end{tabular}

${ }^{\mathrm{a}}$ Described in Duguetia furfuracea; ${ }^{\mathrm{b}}$ described in Duguetia spp.; ${ }^{\mathrm{c} a u t h e n t i c ~ s t a n d a r d ; ~ N o .: ~ c o m p o u n d ~ n u m b e r ; ~} \mathrm{t}_{\mathrm{R}}$ : retention time.
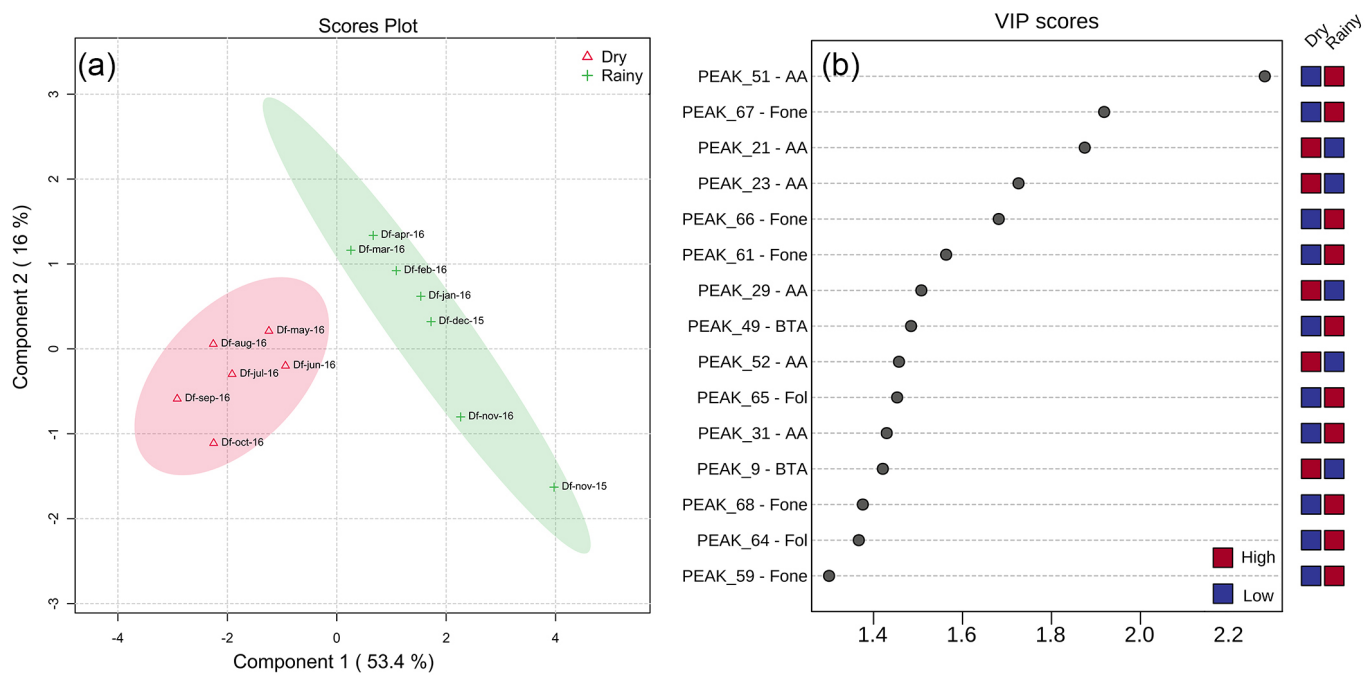

Figure 1. (a) PLS-DA scores plot and (b) VIP scores plot of the mean chemical composition of three specimens of Duguetia furfuracea (Df1, Df2, and Df3), collected between November 2015 and 2016. AA: aporphine alkaloids; BTA: benzyltetrahydroisoquinoline; Fol: flavonol; Fone: flavone. 
climate variation. Cluster A2, especially the branches of compounds $9, \mathbf{1 4}$, and 29; and 21, and 23, tended to be more accumulated in the dry season, while cluster B2, especially the branches of compounds 58,59 , and $66-68 ; 15$, and 49 ; $51,61,62,64$, and 65 ; and 19 and 60 , tended to be more accumulated in the rainy season. On the other hand, cluster A1 (compounds 8, 20, 26, 30, 33, 34, 38, 43, 46, 50, and 57), and cluster B1 (compounds 11, 12, 16,17, 28, 37, 45) were virtually perennial, being of minor importance in the separation of seasons.

To improve the statistical confidence, we decide to evaluate the volcano plot (Figure 3), which considers two tests, the statistical significance ( $p$-value) and the fold change (FC). In general, volcano plot analysis confirmed the pattern observed with HCA (Figure 2) and PLS-DA (Figure 1), higher amounts of 49, 51, 61, 66-68 in the rainy season; compounds 31,64 , and 65 stood out only in $p$-value. In the dry season, compounds $\mathbf{2 1}, \mathbf{2 3}$, and $\mathbf{5 2}$ were significantly accumulated, and compounds $\mathbf{9}$ and $\mathbf{2 9}$ stood out only in $p$-value.

To ascertain if the distribution pattern of the compounds presented in Figures 1-3 influenced the total flavonoids and alkaloids during the seasons, we plotted the sum of peak intensities in Figure 4. In general, the total alkaloid peak intensity exhibited a marked decrease registered in November of both years, being virtually constant between December of 2015 and October of 2016. The rainy season positively influences flavonoids accumulation. The decrease

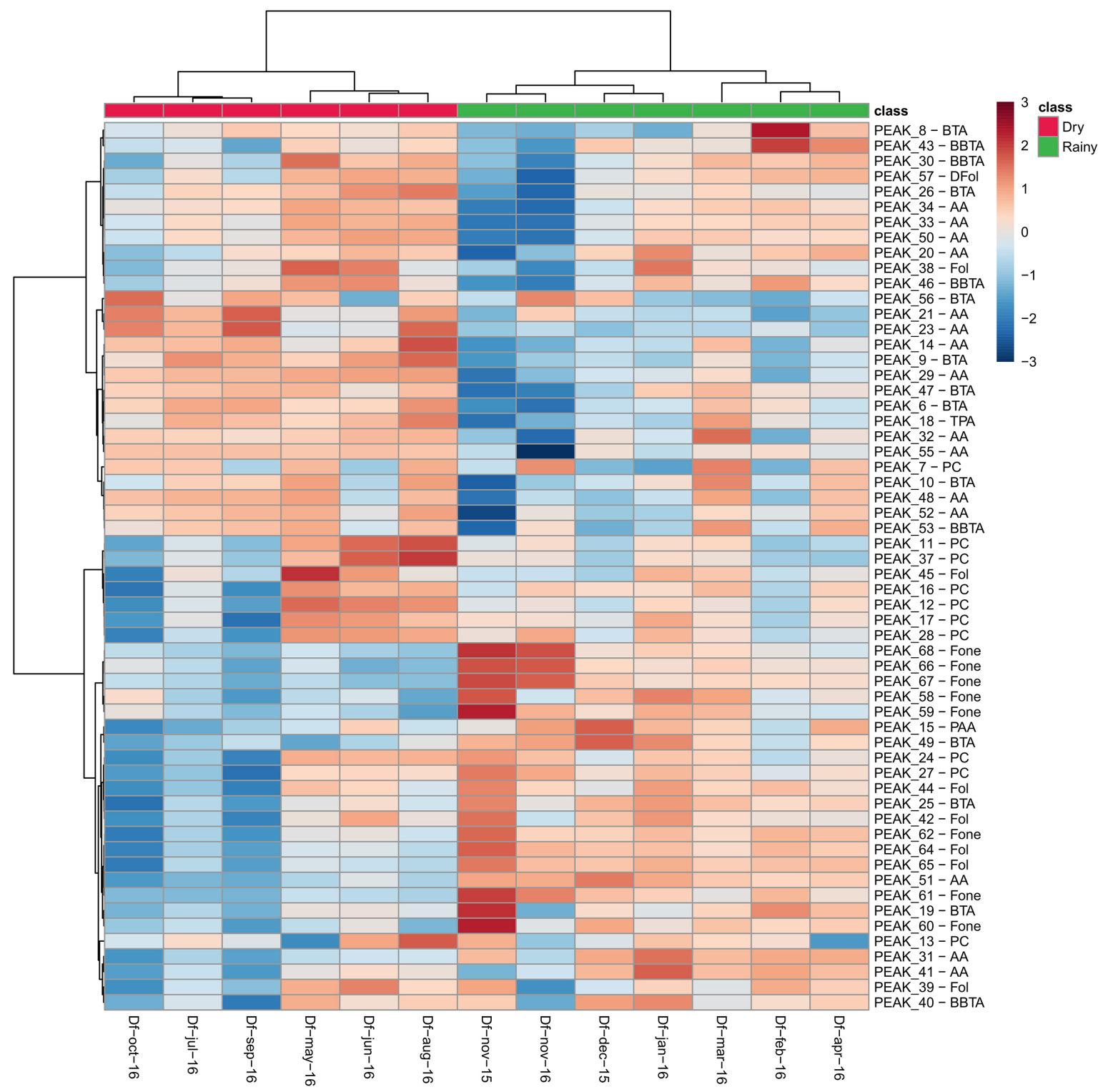

Figure 2. Heatmap from HCA of the mean chemical composition of three specimens of Duguetia furfuracea (Df1, Df2, and Df3), collected between November 2015 and 2016. AA: aporphine alkaloids; BTA: benzyltetrahydroisoquinoline; PAA: proaporphine alkaloids; TPA: tetrahydroprotoberberine alkaloids; BBTA: (bis)benzyltetrahydroisoquinoline; PC: proanthocyanidins. 

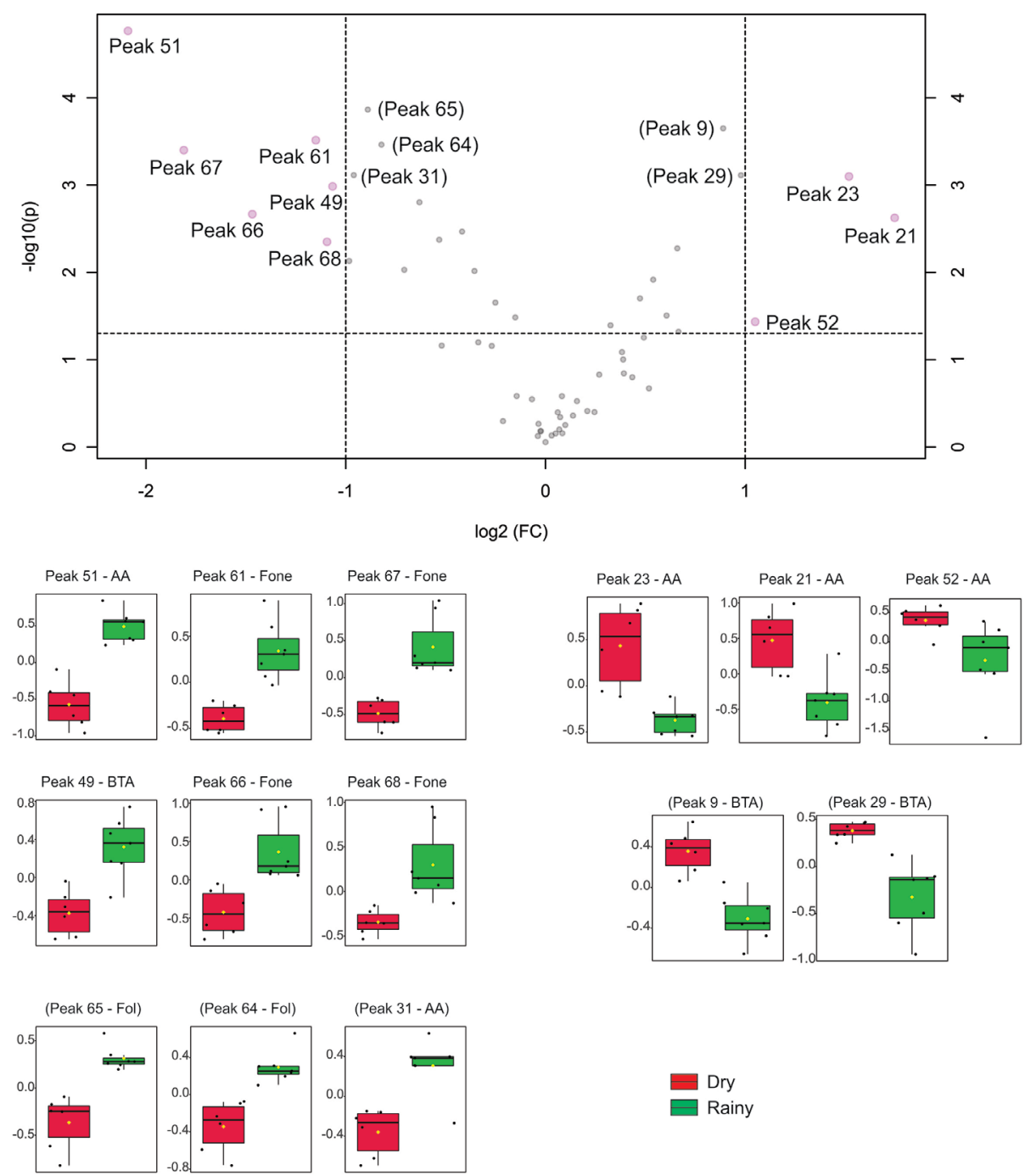

Figure 3. Volcano plot of the mean chemical composition of three specimens of Duguetia furfuracea (Df1, Df2, and Df3) collected between November 2015 and 2016, considering $P$-value threshold of 0.05 and fold change (FC) threshold of 2.0. Peak n: peaks with FC $=1.0$ and $P<0.001$. AA: aporphine alkaloids; BTA: benzyltetrahydroisoquinoline; Fol: flavonol; Fone: flavone.

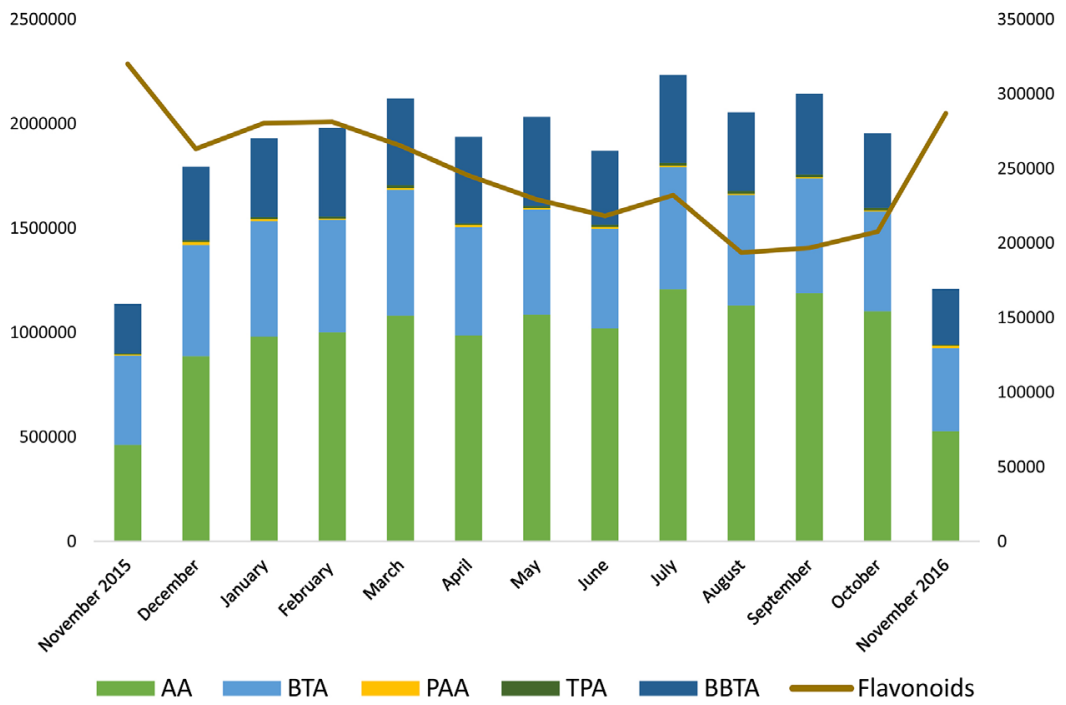

Figure 4. Average monthly accumulated peak intensities obtained with UFLC-MS analysis and arranged by compound class. AA: aporphine alkaloids; BTA: benzyltetrahydroisoquinoline; PAA: proaporphine alkaloids; TPA: tetrahydroprotoberberine alkaloids; BBTA: (bis)benzyltetrahydroisoquinoline. 
in alkaloid content in November coincides with a peak of flavonoid content, suggesting a global metabolism balance.

\section{Metabolite profile and climatic indicators}

We detected two well-established seasons and three transition months by analyzing all climatic indicators, indicating that these periods were not homogeneous (Figure S1, SI section). Therefore, we decided to test whether the compounds or the chemical classes were correlated with $\mathrm{T}_{\mathrm{a}}, \mathrm{H}_{\mathrm{rel}}, \mathrm{DPT}_{\mathrm{a}}, \mathrm{PPT}$, and global radiation $\left(\operatorname{Rad}_{\mathrm{g}}\right)$.

Based on each compound correlation with weather indicators, $\mathrm{DPT}_{\mathrm{a}}$ was the climatic factor that influenced more compounds, followed by $\mathrm{H}_{\text {rel }}, \mathrm{T}_{\mathrm{a}}$ and PPT (Table 2). No correlations with $\operatorname{Rad}_{\mathrm{g}}$ were found. Overall, flavonoids $(42,44,58-62,64-68)$ presented a positive correlation with the climatic indicators, while alkaloids do not exhibit a pattern, presenting eight compounds $(6,9,14,18,21,23$, $29,56)$ negatively correlated and five $(\mathbf{1 5}, \mathbf{1 9}, \mathbf{2 5}, \mathbf{3 1}, \mathbf{5 1})$ positively correlated.

Compounds that presented at least one positive correlation with a weather indicator (Table 2) coincided with the rainy season pattern (Figures 1-3) and tended to have a higher correlation with $\mathrm{DPT}_{\mathrm{a}}$; except for alkaloid 19, which presented correlation only with $\mathrm{T}_{\mathrm{a}}, \mathrm{H}_{\text {rel }}$, and 25, 42, and $\mathbf{4 4}$, that tended to be more accumulated in the rainy season (Figure 2). Despite that, they were also accumulated in May, June, and August, months with high $\mathrm{H}_{\text {rel }}$ (Figure S1, SI section), justifying the higher correlation with $\mathrm{H}_{\text {rel }}$ than with $\mathrm{DPT}_{\mathrm{a}}$ and the previous test's absence.

In contrast, compounds negatively correlated with weather indicators did not exhibit a clear pattern (Table 2).

Table 2. Significant Pearson correlations between peak intensities obtained by UFLC-MS analysis of three specimens of Duguetia furfuracea, and average dew point temperature $\left(\mathrm{DPT}_{\mathrm{a}}\right)$, air temperature $\left(\mathrm{T}_{\mathrm{a}}\right)$, relative humidity $\left(\mathrm{H}_{\mathrm{rel}}\right)$, and total precipitation

\begin{tabular}{|c|c|c|c|c|c|c|c|c|}
\hline \multirow{2}{*}{ No. } & \multicolumn{2}{|c|}{ Dew point temperature } & \multicolumn{2}{|c|}{ Air temperature } & \multicolumn{2}{|c|}{ Relative humidity } & \multicolumn{2}{|c|}{ Total precipitation } \\
\hline & Cor & $P$ & Cor & $P$ & Cor & $P$ & Cor & $P$ \\
\hline \multicolumn{9}{|c|}{ Alkaloids } \\
\hline 6 & -0.6519 & 0.0158 & - & - & - & - & - & - \\
\hline 9 & -0.7969 & 0.0011 & -0.6024 & 0.0294 & - & - & - & - \\
\hline 14 & -0.7651 & 0.0023 & - & - & -0.5988 & 0.0306 & - & - \\
\hline 15 & 0.6450 & 0.0173 & - & - & 0.6259 & 0.0221 & - & - \\
\hline 18 & -0.6504 & 0.0161 & - & - & - & - & - & - \\
\hline 19 & - & - & 0.5931 & 0.0326 & 0.5654 & 0.0440 & - & - \\
\hline 21 & -0.8343 & 0.0004 & -0.6955 & 0.0083 & -0.8132 & 0.0007 & -0.5566 & 0.0482 \\
\hline 23 & -0.8695 & 0.0001 & -0.6121 & 0.0262 & -0.7948 & 0.0012 & - & - \\
\hline 25 & 0.7332 & 0.0043 & 0.5581 & 0.0475 & 0.8230 & 0.0005 & 0.5530 & 0.0500 \\
\hline 29 & -0.6359 & 0.0195 & - & - & - & - & - & - \\
\hline 31 & 0.6988 & 0.0079 & 0.5751 & 0.0398 & 0.6842 & 0.0099 & - & - \\
\hline 51 & 0.8039 & 0.0009 & - & - & 0.6928 & 0.0087 & - & - \\
\hline 56 & - & - & - & - & -0.6429 & 0.0178 & - & - \\
\hline \multicolumn{9}{|c|}{ Flavonols, flavones, and dihydroflavonols } \\
\hline 42 & 0.6180 & 0.0244 & - & - & 0.8282 & 0.0005 & 0.5777 & 0.0387 \\
\hline 44 & 0.7783 & 0.0017 & 0.6902 & 0.0090 & 0.8656 & 0.0001 & 0.5888 & 0.0343 \\
\hline 58 & 0.6228 & 0.0230 & - & - & - & - & - & - \\
\hline 59 & 0.6502 & 0.0161 & - & - & - & - & - & - \\
\hline 60 & 0.6542 & 0.0153 & 0.5664 & 0.0436 & 0.6259 & 0.0221 & - & - \\
\hline 61 & 0.7745 & 0.0019 & 0.6176 & 0.0245 & 0.5956 & 0.0317 & - & - \\
\hline 62 & 0.7927 & 0.0012 & 0.7081 & 0.0068 & 0.7970 & 0.0011 & - & - \\
\hline 64 & 0.8047 & 0.0009 & 0.6746 & 0.0114 & 0.7490 & 0.0032 & - & - \\
\hline 65 & 0.7929 & 0.0012 & 0.6873 & 0.0094 & 0.7246 & 0.0051 & - & - \\
\hline 66 & 0.6547 & 0.0152 & 0.6085 & 0.0273 & - & - & - & - \\
\hline 67 & 0.6893 & 0.0091 & 0.6015 & 0.0297 & - & - & - & - \\
\hline 68 & 0.6562 & 0.0149 & - & - & - & - & - & - \\
\hline
\end{tabular}

Cor: Pearson correlation coefficient; $p<0.005$ significant probability. 
Alkaloids 9, 14, 21, 23, and 29 are consonant with the dry season pattern (Figures 1-3) and negatively correlate with $\mathrm{DPT}_{\mathrm{a}}$.

The analysis of total ion intensity returned a positive correlation only for flavonoids, being correlated with $\mathrm{DPT}_{\mathrm{a}}$ (Pearson correlation $=0.7053, p=0.007)$ and $\mathrm{H}_{\text {rel }}($ Pearson correlation $=0.6667, p=0.01$ ), as expected due to monthly accumulated peak intensities (Figure 4) and the Pearson correlation of peaks and weather indicators.

\section{Discussion}

Many works have described alkaloid production during seasons worldwide; however, few have demonstrated these compounds' specific relationship with climatic indicators, especially those for benzylisoquinoline derivatives. These relationships are also poorly explored in the Brazilian savanna. Here we demonstrate that alkaloid content is virtually constant during the year (Figure 4). Despite that, some alkaloids are found in a more significant proportion in the dry season (Figures $1 \mathrm{~b}$ and 2, cluster A2), especially $\mathbf{9}$, 21, 23, 29, and 52. Few others are more accumulated in the rainy season (Figures $1 \mathrm{~b}$ and 2, cluster B2), such as $\mathbf{5 1 , 4 9}$, and 33 (Figure 3). Castro-Moreno et al. ${ }^{16}$ observed higher content of liriodenine in the roots of Annona lutescens during the dry season. Bala et al. ${ }^{17}$ found that isoquinoline alkaloids accumulated in the roots of Cissampelos pareira in India in the rainy season, even though this country has seasons widely different from those in the Cerrado. Following these observations, we can highlight seasons' influence on various tyrosine-derived alkaloids in different locations with distinct climates.

Figures 2 and 4 show the tendency of flavonoids to accumulate more during the rainy season than during the dry season, especially the flavones 61, 66-68 and flavonols 64, 65 (Figure 3), consistent with the findings of a vast scientific literature that links these compounds with the protection of plant tissues from UV radiation and reactive oxygen species. Interestingly, Guidi et al. ${ }^{18}$ showed that UV radiation had induced a decrease in carotenoids and raised flavonoid biosynthesis. Since both compound classes are responsible for UV-protection, the increase in flavonoid production might be a compensatory response. ${ }^{18}$ However, none of the detected flavonoids presented a correlation with $\operatorname{Rad}_{\mathrm{g}}$, being DPT the most representative weather indicator for this class (Table 2).

DPT represents the temperature at which the air must reach a certain pressure to saturate and form dew, meaning that this parameter represents the interaction of three others: air temperature, relative humidity, and atmospheric pressure. ${ }^{19}$ Some studies also use this parameter to estimate the total solar radiation, which makes this an essential climatic indicator for understanding seasonal climatic variation..$^{20}$ As expected by the DPT composition, ${ }^{19} \mathrm{~T}_{\mathrm{a}}$ and $\mathrm{H}_{\text {rel }}$ presented a correlation with flavonoid content (Table 2). Sampaio et al. ${ }^{21}$ showed that flavonoids and tannins in the leaves of Lafoensia pacari, another species from the Cerrado, were also positively correlated with temperature.

The accumulation of flavonoids tended to be low during the dry season, except in July. In November of 2015 and 2016, a peak in flavonoids accumulation and a marked decrease in the alkaloid was detected, contrasting with the perennial pattern of the other months (Figure 4). Flavonoids and other cinnamic acid derivatives are produced from phenylalanine, and BTA derivatives are biosynthesized from tyrosine. Manela et al..$^{22}$ suggested that phenylalanine concentrations are rate-limiting in the production of flavonoids instead of the overexpression of the enzymes involved in their biosynthesis. In general, plants produce phenylalanine and tyrosine from arogenate. However, Yoo et al.$^{23}$ showed that similar to microorganisms, plants can convert tyrosine to phenylalanine using a cytosolic phenylpyruvate aminotransferase. Considering these facts together, the odd decrease in alkaloid production in November was most likely due to the necessity of flavonoid production and tyrosine consumption to produce phenylalanine.

Given the distribution pattern of compounds found in the present work, we can suggest that herbal medicine's quality with activities associated with flavonoids can be attested by total flavonoid content in D. furfuracea once flavonoids tend to vary together (Figure 2). On the other hand, alkaloids presented perennial trends, but with qualitative variation, the quality activities associated with these compounds must be attested with more specific methods.

Santos et al. ${ }^{15}$ reported a flavonoid and alkaloid-rich extract as an anti-inflammatory, associating it with the ethnopharmacological use as antirheumatic. The authors also isolated dicentrinone and showed that this compound contributes to this activity. Despite that, the importance of flavonoids from $D$. furfuracea for antirheumatic activity is still unclear and might be enlightened for a rational quality control method proposition. Furthermore, we did not detect the alkaloids duguetine, dicentrinone, and $\mathrm{N}$-methylglucamine, pointed by Santos et al. ${ }^{15}$ as the major compounds in the anti-inflammatory extract. ${ }^{15}$ Carollo et al..$^{24}$ reported two chemotypes of $D$. furfuracea by analyzing the essential oil composition of some specimens. However, the variation in nonvolatile metabolites remains unexplored. These results bring a question whether the absence in our analysis of these alkaloids detected by 
Santos et al. ${ }^{15}$ is due to geographical or chemotype variation and must be explored in future works.

\section{Conclusions}

In summary, a seasonal pattern in the accumulation of flavonoids and alkaloids was observed, indicating that flavonoids were present at higher abundances in the rainy season than in the dry season, and the alkaloid content tended to be stable during the year, despite the qualitative variation. Further, climatic factors and compound accumulation showed significant correlations, helping explain the seasonal variation. Among the climatic factors, $\mathrm{DPT}_{\mathrm{a}}$ seemed to be the most predictive, probably because this factor results from the interaction of other climatic factors. As a result, this study demonstrated the importance of elucidating climate effect on the metabolic variation, especially for popular medicine species or that contain economic interest compounds.

\section{Experimental}

\section{Chemicals and reagents}

Ultrapure water was prepared by a Direct-Q system (Millipore, Billerica, MA, USA), high-performance liquid chromatography (HPLC)-grade acetonitrile (SigmaAldrich, Saint Louis, USA) and methanol (Phillipsburg, NJ, USA) and American Chemical Society (ACS)-grade formic acid (Sigma-Aldrich, Darmstadt, Germany) were used for extraction and ultra-fast liquid chromatography (UFLC) analysis.

\section{Study area}

The Private Natural Heritage Reserve of the Federal University of Mato Grosso do Sul (RPPN/UFMS) is situated between the coordinates $20^{\circ} 30^{\prime} \mathrm{S}$ and $54^{\circ} 36^{\prime} \mathrm{W}$ in the municipality of Campo Grande, MS, Brazil. This reserve of approximately 50 ha is an urban fragment of Cerrado. ${ }^{25}$ This fragment is under regeneration, and consequently, some exotic species are present in this area. However, most vegetation in this fragment is typical of the Cerrado, being mainly composed of tall trees transitioning to grassland, with some shrubs and small trees, where D. furfuracea (Annonaceae) is usually found.

The studied area's climate presents two distinct seasons, a dry season, generally from May to September, and a rainy season, generally from October to April. ${ }^{11}$ In this research, however, we used climatic data specific to the period when the study occurred. We performed statistical analysis to classify the months, which will represent the dry and rainy seasons. This climatic information was provided by the National Institute of Meteorology (INMET) of the Brazilian government. The data considered for statistical analysis of seasonality were air temperature (average, maximum and minimum- $\mathrm{T}_{\mathrm{a}}, \mathrm{T}_{\max }$, and $\mathrm{T}_{\min }$ ), dew point temperature (average, maximum and minimum-DPT , $\mathrm{DPT}_{\text {max }}$, and $\mathrm{DPT}_{\text {min }}$ ), total precipitation (PPT), relative humidity $\left(\mathrm{H}_{\mathrm{rel}}\right)$, atmospheric pressure (AP) and global radiation $\left(\operatorname{Rad}_{\mathrm{g}}\right)$ registered during the ten days before each collection. These data were log-transformed, scaled by mean centering, and submitted to both principal component analysis (PCA) and hierarchical clustering analysis (HCA) on the MetaboAnalyst 4.0 platform. ${ }^{26}$

\section{Plant material}

Three biological replicates of $D$. furfuracea (Annonaceae) were selected, and the vouchers were deposited into the herbarium at the Federal University of Mato Grosso do Sul (CGMS), Mato Grosso do Sul, Brazil. The coordinates of each specimen and other collection information are provided in Table 3.

Table 3. GPS coordinates of the plants collected for this study

\begin{tabular}{lccc}
\hline Specimen & Coordinates & Altitude / m & $\begin{array}{c}\text { Voucher } \\
\text { No. }\end{array}$ \\
\hline 1 & $20^{\circ} 30^{\prime} 491^{\prime \prime}$ S, 054'36'860" W & 546 & 75814 \\
2 & $20^{\circ} 30^{\prime} 494^{\prime \prime}$ S, 054'36'864" W & 535 & 75812 \\
3 & $20^{\circ} 30^{\prime} 424^{\prime \prime}$ S, 054'36'860” W & 539 & 75815 \\
\hline
\end{tabular}

A branch including young and mature leaves was collected monthly, in the morning, between November 2015 and November 2016. The number of branch samples obtained per individual was 13 , resulting in 39 samples in total. These branches were separated and dried in a circulating-air oven at a temperature of $50{ }^{\circ} \mathrm{C}$ for $48 \mathrm{~h}$. The dry leaf tissue was ground and homogenized into a powder with an analytical mill (basic analytical mill IKA ${ }^{\circledR}$-A11, Wilmington, NC, USA). An aliquot of this powder was then crushed in a mixer mill (Retsch ${ }^{\circledR}-\mathrm{MM} 400$, Haan, Germany) to standardize grain size. The crushed powder was used for the preparation of extracts.

\section{Preparation of extracts}

All leaf extracts of samples from $D$. furfuracea used in the metabolomic analysis were prepared randomly using $40 \mathrm{mg}$ of powdered material. This powder was extracted with $4 \mathrm{~mL}$ of methanol:water $(7: 3 \mathrm{v} / \mathrm{v}$, with $0.1 \%$ formic acid 
added $25 \mu \mathrm{g} \mathrm{mL} \mathrm{m}^{-1}$ of caffeine as internal standard). These samples were extracted in an Elmasonic E $30 \mathrm{H}$ ultrasonic bath (Singen, Germany) for $15 \mathrm{~min}$; subsequently, they were centrifuged at 3,500 $\mathrm{rcf}$ for $10 \mathrm{~min}$, the supernatant was filtered through polytetrafluoroethylene (PTFE) syringe filters $\left(\right.$ Millex $^{\circledR} 0.22 \mu \mathrm{m} \times 3.0 \mathrm{~mm}$, Millipore, Carrigtwohill, Ireland). These extracts were immediately analyzed by UFLC-diode array detection (DAD)-MS.

\section{UFLC-DAD-MS analysis}

The extracts were analyzed through an LC-20AD (Shimadzu, Kyoto, Japan) coupled to a diode array detector and electrospray ionization quadrupole time-of-flight (ESI-qTOF) mass spectrometer (MicroTOF-Q III, Bruker Daltonics, Billerica, USA). The chromatographic column used was a Kinetex ${ }^{\circledR}$ C-18 $(2.6 \mu \mathrm{m}, 150 \times 2.2 \mathrm{~mm}$, Phenomenex ${ }^{\circledR}$ ) protected by a precolumn packed with the same material, which was in an oven with the temperature set at $50{ }^{\circ} \mathrm{C}$. The mobile phase was ultrapure water (solvent A), and acetonitrile (solvent B), both mixed with $0.1 \%$ formic acid $(\mathrm{v} / \mathrm{v})$, and the gradient elution profile was as follows: $0-2 \mathrm{~min}, 3 \%$ of $\mathrm{B}$; $2-25 \mathrm{~min}, 3-25 \%$ of $\mathrm{B}$; and $25-40 \mathrm{~min}, 25-80 \%$ of $\mathrm{B}$, followed by washing and reconditioning of the column $(8 \mathrm{~min})$. The flow rate was $0.3 \mathrm{~mL} \mathrm{~min}^{-1}$, and the injection volume was $1 \mu \mathrm{L}$. The analysis was performed by monitoring the ultraviolet (UV) wavelength between 240 and $800 \mathrm{~nm}$ and a mass spectrometer operating in negative and positive ion modes $(m / z, 120-1,200)$. The capillary voltage applied was $4,500 \mathrm{kV}$, and nitrogen was employed as the nebulizer gas (4 Bar) and drying gas $\left(9 \mathrm{~L} \mathrm{~min}^{-1}\right)$. Data were processed in DataAnalysis 4.2 (Bruker Daltonics, Billerica, USA).

Multivariate statistical analysis of LC-MS data and compound identification

The positive mode was selected for the metabolomic analyses once both alkaloids and flavonoids were detected in this mode, and most alkaloids were not detected in the negative mode. The metabolomic experiment was performed by injecting each leaf extract (39 samples) randomly under UFLC-DAD-MS positive mode. To evaluate the efficiency of the equipment and the stability of compounds during the experiment, a pool of samples was prepared, mixing $10 \mu \mathrm{L}$ of each leaf extract, and injected every ten samples during the metabolomic experiment. The pooled samples were also used for data alignment and compound identification by acquiring UFLC-DAD-MS/MS data.

Compound identification was performed based on the
UV spectra, accurate mass (MS), and ion fragmentation profile (MS/MS) by comparing these data with information reported in the literature. MS and MS/MS data for the identification were based on positive and negative modes. The identification of anonaine and epicatechin was confirmed through the injection of authentic standards.

The ion peaks were aligned, applying MetAlign software, ${ }^{27}$ and MSClust ${ }^{28}$ software was used to reduce the number of entrances. After that, the mean peak intensities were obtained for all peaks of the biological replicates. Peaks with intensities below 5000 in all samples were excluded, generating 78 compounds. A matrix containing peaks relative to alkaloids, flavonoids, and proanthocyanidins (58 entrances) was analyzed on the MetaboAnalyst 4.0 platform ${ }^{26}$ and submitted to statistical analyses, such as partial least squares-discriminant analysis (PLS-DA), hierarchical clustering analysis (HCA), volcano plot analysis and pattern analysis. For these analyses, data were log-transformed, Pareto scaled, and normalized by the median. For the compounds and HCA dispersion profile, data were organized using the Pearson distance and Ward algorithm. A box plot was applied to evaluate the ion intensity distributions among specimens. Finally, the climatic information $\left(\mathrm{T}_{\mathrm{a}}, \mathrm{DPT}_{\mathrm{a}}, \mathrm{PPT}, \mathrm{H}_{\mathrm{rel}}\right.$ and $\mathrm{Rad}_{\mathrm{g}}$ ) was inserted into the input array. Positive and negative correlations with each peak were determined by applying Pearson correlation (Cor $\geq \pm 0.5000 \mid$ and $p \leq 0.05$ ).

Legal aspects

The project is registered in the National System for the Management of Genetic Heritage and Associated Traditional Knowledge (SisGen) under the protocol A15EB96.

\section{Supplementary Information}

Supplementary information (season period evaluation and chemical dereplication) is available free of charge at http://jbcs.sbq.org.br as PDF file.

\section{Acknowledgments}

This work was supported by Conselho Nacional de Desenvolvimento Científico e Tecnológico (CNPq) (grant number 309054/2016-8; 307463/2018-4), Coordenação de Aperfeiçoamento de Pessoal de Nível Superior (CAPES) (grant number 88882.317360/2019-01), Fundação de Apoio ao Desenvolvimento do Ensino, Ciência e Tecnologia do Estado de Mato Grosso do Sul (Fundect) (grant number 50/300.174/2016) and Instituto Nacional de Ciência e 
Tecnologia em Áreas Úmidas (INAU) (grant number 421733/2017-9).

\section{Author Contributions}

CAC, AGB, DBS and JMS were responsible for the conceptualization; ALM, ANS, and AGB for formal analysis and investigation; CAC, AGB and ALM for data curation; ALM for writing the original draft; CAC for project administration. All authors did the writing-review and editing.

\section{References}

1. Agra, M. F.; Silva, K. N.; Basílio, I. J. L. D.; Freitas, P. F.; Barbosa-Filho, J. M.; Rev. Bras. Farmacogn. 2008, 18, 472.

2. Bundy, J. G.; Davey, M. P.; Viant, M. R.; Metabolomics 2008, 5,3 .

3. Gobbo-Neto, L.; Lopes, N. P.; Quim. Nova 2007, 30, 374.

4. Chen, Y.-J.; Lin, C.-Y.; Hsu, H.-W.; Yeh, C.-Y.; Chen, Y.-H.; Yeh, T.-F.; Chang, S.-T.; Plant Physiol. Biochem. 2019, 142, 405.

5. Borella, J. C.; Duarte, D. P.; Novaretti, A. A. G.; Menezes Jr., A.; França, S. C.; Rufato, C. B.; Santos, P. A. S.; Veneziani, R. C. S.; Lopes, N. P.; Rev. Bras. Farmacogn. 2006, 16, 557.

6. Alvarenga-Venutolo, S.; Rosales-López, C.; SánchezChinchilla, L.; Muñoz-Arrieta, R.; Aguilar-Cascante, F.; Phytochemistry 2018, 151, 26.

7. Ben Ahmed, Z.; Yousfi, M.; Viaene, J.; Dejaegher, B.; Demeyer, K.; Mangelings, D.; Heyden, Y. V.; Pharm. Biol. 2017, 55, 1185.

8. Bertolucci, S. K. V.; Pereira, A. B. D.; Pinto, J. E. B. P.; Oliveira, A. B.; Braga, F. C.; Chem. Biodiversity 2013, 10, 288.

9. Ko, H. C.; Lee, J. Y.; Jang, M. G.; Song, H.; Kim, S.-J.; Ind. Crops Prod. 2018, 122, 506.

10. Hogedal, B. D.; Molgaard, P.; Biochem. Syst. Ecol. 2000, 28, 949.

11. Ratter, J. A.; Ribeiro, J. F.; Bridgewater, S.; Ann. Bot. 1997, 80, 223.

12. Myers, N.; Mittermeier, R. A.; Mittermeier, C. G.; da Fonseca, G. A. B.; Kent, J.; Nature 2000, 403, 853.
13. Ministry of Environment, O Bioma Cerrado, https://antigo. mma.gov.br/biomas/cerrado, accessed on May 12 $2^{\text {th }}, 2021$.

14. http://floradobrasil.jbrj.gov.br/jabot/floradobrasil/FB110313, accessed on April 1 1 ${ }^{\text {st }}, 2019$.

15. Santos, R. C.; Souza, A. V.; Andrade-Silva, M.; Vera Cruz, k. C.; Leite Kassuya, C. A.; Lima Cardoso, C. A.; Vieira, M. C.; Formagio, A. S. N.; J. Ethnopharmacol. 2018, 211, 9.

16. Castro-Moreno, M.; Tinoco-Ojangurén, C. L.; Cruz-Ortega, M. R.; González-Esquinca, A. R.; J. Plant Res. 2013, 126, 529.

17. Bala, M.; Kumar, S.; Pratap, K.; Verma, P. K.; Padwad, Y.; Singh, B.; Nat. Prod. Res. 2017, 33, 622.

18. Guidi, L.; Brunetti, C.; Fini, A.; Agati, G.; Ferrini, F.; Gori, A.; Tattini, M.; Environ. Exp. Bot. 2016, 127, 14.

19. Wallace, J. M.; Hobbs, P. V.; Atmospheric Science: An Introductory Survey, vol. 92, $2^{\text {nd }}$ ed.; Academic Press: San Diego, USA, 2006.

20. Ekici, C.; Teke, I.; Energy Sources, Part A 2019, 41, 1344.

21. Sampaio, B. L.; Bara, M. T. F.; Ferri, P. H.; Santos, S. C.; de Paula, J. R.; Rev. Bras. Farmacogn. 2011, 21, 1127.

22. Manela, N.; Oliva, M.; Ovadia, R.; Sikron-Persi, N.; Ayenew, B.; Fait, A.; Galili, G.; Perl, A.; Weiss, D.; Oren-Shamir, M.; Front. Plant Sci. 2015, 6, 538.

23. Yoo, H.; Widhalm, J. R.; Qian, Y.; Maeda, H.; Cooper, B. R.; Jannasch, A. S.; Gonda, I.; Lewinsohn, E.; Rhodes, D.; Dudareva, N.; Nat. Commun. 2013, 4, 2833.

24. Carollo, C. A.; Hellmann, A. R.; Siqueira, J. M.; Biochem. Syst. Ecol. 2005, 33, 647.

25. Environment Institute of Mato Grosso do Sul Reserva Particular do Patrimônio Natural (RPPN), https://www.imasul.ms.gov.br/ reserva-particular-do-patrimonio-natural-rppn/, accessed on May $12^{\text {th }}, 2021$.

26. Chong, J.; Soufan, O.; Li, C.; Caraus, I.; Li, S.; Bourque, G.; Wishart, D. S.; Xia, J.; Nucleic Acids Res. 2018, 46, W486.

27. Lommen, A.; Anal. Chem. 2009, 81, 3079.

28. Tikunov, Y. M.; Laptenok, S.; Hall, R. D.; Bovy, A.; de Vos, R. C.; Metabolomics 2012, 8, 714.

Submitted: February 22, 2021

Published online: May 21, 2021 